\title{
Chapter

\section{An overview of water quality indices as promising tools for assessing the quality of water resources}

\author{
Vishal Kamboj, Nitin Kamboj* and Aditi Bisht \\ Department of Zoology and Environmental Science, Gurukula Kangri (Deemed to be University), \\ Haridwar 249404, Uttarakhand, India
}

\begin{abstract}
The unsustainable interference of anthropogenic activities such as industrialization, urbanization, tourism, mining, agriculture sector deterioration the water resources. Day by day the quality of the water resources is declined and that creates many problems such as disturbing the aquatic life, human health, and other intended uses. In the middle of the 1960s, a tool i.e. water quality indices developed to assess the water quality of the water body simply and understandably. The WQI value depends on the water quality parameters such as physico-chemical, heavy metal, and biological parameters. Each water quality parameter plays an important role in describing the quality of the water resources. The monitoring of pollution sources i.e. point and non-point sources in the water body is expensive and difficult. Nowadays, a total of $33 \mathrm{WQI}$ are available, who show the quality of a water body by ranking i.e. very good, good, poor, and very poor. Each WQI shows their property and some are developed on a regional or local area basis. So, in this chapter, we discuss the commonly used WQI throughout the world which is used for ranking the water quality. The present overview indicates the basic concept and steps, advantages, and disadvantages of the WQI.
\end{abstract}

\section{Keywords}

ATI, CCME, NSF, OIP, Water quality indices, Water resources

$\nabla$ Nitin Kamboj, Email: kambojgurukul@gmail.com ( ${ }^{*}$ Corresponding author) 


\section{Introduction}

As we know, of all-natural resources, water is the most precious and essential source in which life begins and nurtured. Water is important for the survival of all organisms. Although most of the plants, animals, and humans contain more than $70 \%$ of water. According to scientists, around $71 \%$ of the earth's surface is covered by the water and divided into two broad categories mainly freshwater $(2.5 \%$ of all this water) and saltwater (97.5\% of all this water). A $97.5 \%$ of salt water is present in the oceans and seas which is unfit for the drinking. Besides, $2.5 \%$ of freshwater, around $69 \%$ present in the glacier and ice caps, $30 \%$ is groundwater and $1 \%$ is surface water and soil moisture seen in Figure 1. Freshwater is vitally important for the living being for their survival and daily needs. The major part of freshwater is tied up in glacier and with the melting of the glacier, the create the glacier-fed rivers or streams (Kamboj et al., 2020). In the whole world, most of the cities/ township is set up near the water body. Human beings used these water resources for their daily needs such as food, transportation, irrigation, industry. and a lot of things. In the last three decades, the demand for water resources is high due to population growth, urbanization, and industrialization (Ogunlela Adelodun, 2014; Kumar et al., 2018).

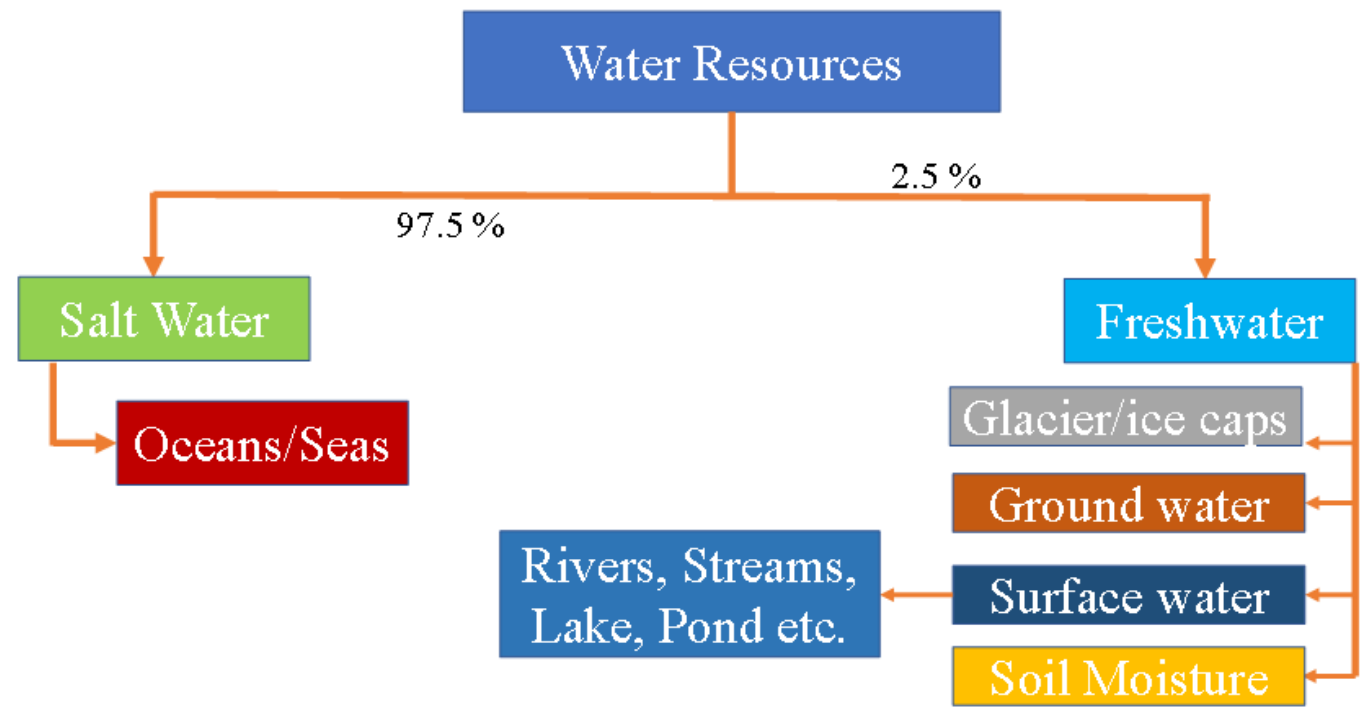

Figure 1. Distribution of water resources on planet earth. 
The higher water demand depletes the quality and quantity of water resources. Waste generated by the urbanization and industrialization sector directly dumped and it affects the surface water resources. Besides, some industries dumped their untreated wastewater into the earth's surface which affects the groundwater aquifers (Kamboj and Choudhary, 2013; Choudhary et al., 2014; Kamboj et al., 2015). However, the direct dumping of sewage and industrial wastewater in the surface water resources such as rivers, streams, ponds, lakes, directly and indirectly, affects the quality of the water. Once the quality of surface water resources is depleted it affects the aquatic fauna and flora (Kamboj and Kamboj, 2020).

\section{Water quality and water quality index (WQI)}

Water quality is one of the vital components to maintaining water resources management. The water quality of a water body is classified on the three basic categories such as physical, chemical, and biological parameters. Each category contains several parameters that are assessed by the monitoring that provides the basic data for detecting the condition of water quality of the water resources (Gazzaz et al., 2012). The monitoring of pollution sources i.e. point and non-point sources in the water body is expensive and difficult. The monitoring data of the pollution source showed the types of pollutants and their trend of a water body for the water quality authorities for making recommendations for the future prospective (Sutadian et al., 2016). Besides, the monitoring of the water quality parameters difficulty defining the quality of water resources merely. This type of condition is creating due to the complexity of factors, and a large number of parameters are used for showed the water quality. However, in the mid of 1960s, an indexing tool called water quality index (WQI) is developed for show the water quality of the water resources basically for rivers, lakes, ponds, and groundwater. In the WQI tool, the monitoring data of selected parameters is aggregating in a simple form for expressing the water quality. Besides, the WQI tool has become important and mostly used for assessing the status of water quality of any water resources worldwide. Since the 1960s to till, a lot of WQI has been developed and formulated by many scientist and researchers.

\section{Common steps for formulation and development of the WQI}

For the formulation and development of a WQI, the common steps are following (Figure 2):

1. Selection of water quality parameters

2. Transformation of parameters on a common scale for obtaining sub-indices

3. Assigning weight of selected parameters

4. Sub-indices aggregation for the final index score

\section{Selection of water quality parameters}

The selection of parameters is the keen part of a WQI. As we know, water consists a lot of constituents 


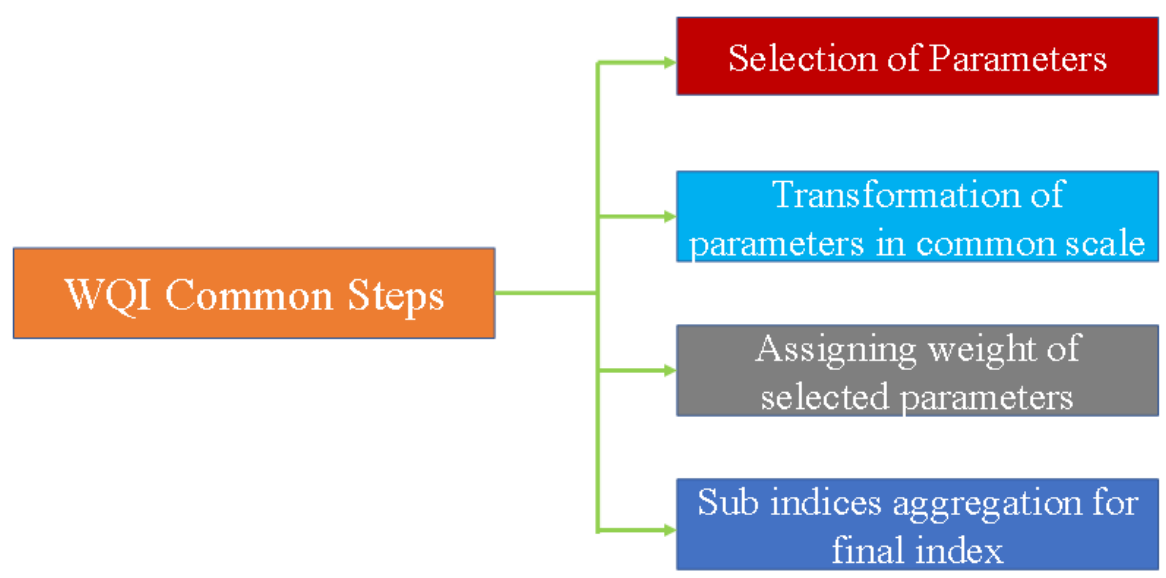

Figure 2. Common steps used for the computation of WQIs.

including elements in the form of metals, non- metal, metalloids, anions mainly carbonate and bi-carbonates, sulphate, nitrate, etc, organics such as pesticides as well as other organics and suspended particles (Abbasi and Abbasi, 2012). In WQI, the parameters have selected from a range of four parameters to twenty-six parameters. Abbasi and Abbasi (2012) told that no method show the 100\% accuracy for parameters selection. According to the literature survey, mostly the selection of parameters for WQIs is based on the type of system used i.e. fixed, mixed and open system.

In a fixed system, a fixed set of parameters is used for a particular water resource. For e.g., if we compared the water quality of two rivers then we selected a fixed set of parameters for both rivers. Most of the WQIs have used a fixed set of parameters (Cude, 2001; Abbasi and Abbasi, 2012; Almeida et al., 2012). However, in an open system, we are selected a minimum number of parameters based on their characteristics and impacts on the environment. Most of the WQIs did not define the guidelines for parameters selection because the parameters are varied from one place to another place (Swamee and Tyagi, 2007; Sutadian et al., 2016). While in a mixed system, we are selected basic and some additional parameters i.e. toxic parameters. In this system, additional parameters are used when the addition parameters show the higher sub-indices value than the aggregated index value of basic parameters in the final index calculation (Hanh et al., 2011, Sutadian et al., 2016).

Key points for parameters selection: Keeping the view of parameters selection for WQIs, there are some points is noted by the researcher before selection of parameters for a WQIs (Cude, 2001; Kannel et al., 2007; Hanh et al., 2011) are as follow:

- Parameters that show a higher influence on water quality.

- According to the survey of literature review.

- According to the data availability. 
- Parameters that show the overall quality of the water resource.

- Expert judgement is the selection of parameters based on interactive groups, individuals' interview, and Delphi method (Linstone and Turoff, 2002; Juwana et al., 2010).

- Statistical method: In this method, Pearson's correlation and factor analysis or principal component analysis are used for the selection of significant parameters. In this, we are eliminated that parameters that show the highest correlation with others. In a study, ammonia and orthophosphate were eliminated due to the positive significant correlation with chemical oxygen demand (Debels et al., 2005). Besides, in the PCA/PFA method, only those parameters are selected which show the higher loading factors for subsequent analysis (Gazzaz et al., 2012).

\section{Transformation of parameters on a common scale for obtaining sub-indices}

In this part, the parameters are converting into a common scale for making sub-indices. The transforming of the parameters in a common scale is based on the two important factors: one is the difference in parameter's unit and second is the difference in the range of concentration of the parameters (Abbasi and Abbasi, 2012). In the water sample, the measuring unit of parameters is different. Physical parameters such as turbidity electrical conductivity and water temperature are measure in Nephelometric turbidity unit (NTU), micro-ohm $(\mu \mathrm{m} / \mathrm{S})$ and degree Celsius $\left({ }^{\circ} \mathrm{C}\right)$, respectively, most chemical parameters measure in part per million (ppm) and microbial parameters measure in numbers. However, the range of concentration of the parameters is different. We all know, in a water sample, the range of the dissolved oxygen is 0 to $12 \mathrm{mg} / \mathrm{l}$ but parameters such as BOD, COD, Sodium and many others have present in different ranges. Besides, the presence of some elements such as mercury in the water sample is best for drinking purpose when the concentration is beyond 0.001 $\mathrm{mg} / \mathrm{l}$. If the concentration of mercury is twice or more than $1 \mathrm{mg} / \mathrm{l}$ is not fit for human consumption (Sutadian et al., 2016). So, for keeping these factors, converting the parameters to a common scale for making sib-indices is a need.

Development and types of Sub-indices: In mostly WQI index, the sub-indices of each parameter are developed for converting the different parameters unit and their ranges in a single scale. The common steps for converting the parameters in a single scale is illustrated in Figure 3. In a water sample, the are many parameters. So, we assigned a series of parameters variable for example $\left(X_{1}, X_{2}, X_{3}, . . X_{n}\right)$ and then for each parameter $\left(X_{n}\right)$ a sub-index i.e. $I_{i}$ is computed by using the function $f(x)$ and the sub-index equation is given below:

$I i=F_{n}\left(X_{n}\right)$

Eq. 1

After sub-index of parameters, the next process is the aggregation. In the aggregation process, 


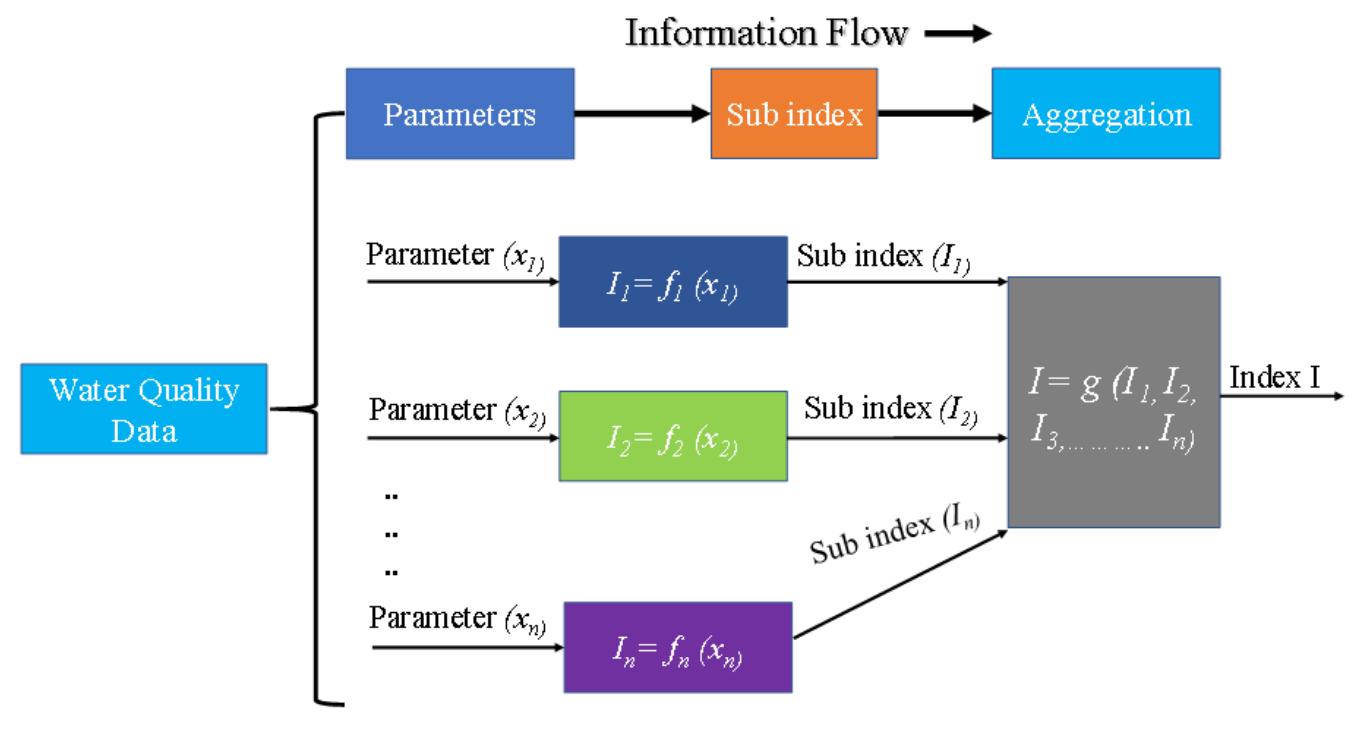

Figure 3. Basic development process of sub-indices for an index.

generally, we adding all the sub-index value and finalize a final index using Eq. 2.

$I=g\left(I_{1}, I_{2}, I_{3} \ldots I_{n}\right)$

Eq. 2

Types of Sub-indices: According to Abbasi and Abbasi (2012), the sub-indices is classified into four types such as Linear, Non-linear, Segmented linear and Segmented non-linear. The basic knowledge or features of all types is listed below:

- Linear Sub-indices: The linear equation is the simplest sub-indices function for converting the parameters into a single scale by the equation i.e. $I=a x+b$. Where $I$ is the sub-index, $x$ is the parameters variable, $a$ and $b$ the constants. This function method is easily computed and showed a direct proportion of exits between the parameter's variable and sub-index. The only limitation of this sub-index is limited flexibility.

- Non-linear Sub-indices: Non-linear sub-indices are applying when the cause-effect relationship of parameters does not vary linearly. When plotted this relationship on the graph sheet it seen like the curvature. Generally, two types of non-linear indices are describing such as implicit and explicit function. In implicit function, there is no mathematical equation is given but in explicit function mathematical equation is given. The basic formula used for the implicit function is $I_{i}=x^{c}$ where $c$ is constant and it is $\neq 1$, and $x$ is the parameter variable (Brown et al., 1970). The explicit or exponential function, the basic formula is used $I_{i}=C^{x}$, where $C$ is the constant and $\mathrm{x}$ is the 
parameter variables. In explicit function, generally in the base of logarithm constant used is either 10 or e (Abbasi and Abbasi, 2012).

- Segmented linear function sub-indices: The sub-indices are applicable when the two or more straight-line segments in the threshold level or point break level. It is more flexible and specially used for the standard limit provided by the agencies such as BIS, WHO. The important thing of the sub-indices in the step function. So, it also called a dichotomous function. The basic formula of the segmented linear sub-indices is

$$
I_{i}=\frac{\left(b_{i+1}-b_{i}\right)}{\left(a_{i+1}-a_{i}\right)}\left(x-a_{i}\right)+b_{i}
$$

Where, $a_{i}<x<a_{\mathrm{i}+1} ; \mathrm{i}=1,2,3 \ldots n ; a_{i}$ and $b_{i}$ is the threshold level.

It also consists of a steps series, which gives the multiple state function seen in Table 1.

The sub-indices do not apply to the situation where the slope is increased by increase the pollution variables.

- Segmented non-linear function sub-indices: It consists of two or more-line segment in which one line segment is non-linear. Each segment consists of a different equation which covers a range of pollution parameter variables. It is the most flexible sub-indices which has been used most of the water quality sub-indices. The example of the segmented non-linear function sub-indices is illustrated in Table 2.

\section{Assigning weight of selected parameters}

This step plays a vital role in a water quality index. The assigning weight of the parameter is confusion task because of the selection of parameters. Some water quality parameters such as dissolved oxygen, turbidity, transparency, colour, etc are very important parameters for express the surface water quality while these parameters are not useful to express the quality of groundwater.

Table 1. Segmented linear function used by Horton (1965) for dissolved oxygen.

\begin{tabular}{lll}
\hline Segment & Range of $I$ for $x$ & Saturation \\
\hline 1 & $I=0$ & $<10 \%$ \\
2 & $I=30$ & $10 \%-30 \%$ \\
3 & $I=100$ & $>70 \%$ \\
\hline
\end{tabular}

Table 2. Segmented non-linear function used by Prati et al. (1971) for dissolved oxygen.

\begin{tabular}{lll}
\hline Segment & Range of $x$ & Equation \\
\hline 1 & $50<x<100$ & $I_{i}=8(100-Y)$ \\
2 & $x<100$ & $I_{i}=8(Y-100)$ \\
\hline
\end{tabular}


So, the weight of the parameters is assigned based on their importance and their effect on the water quality index value (Abbasi and Abbasi, 2012; Sutadian et al., 2016). In mostly WQI, the equal weight of parameters is assigned when parameters are equally important whereas if the parameters are lesser or greater importance than the weight of parameter assigned unequal weight. Besides, the basic thing for assign the parameters weight is depending on the index developer, parameter selection and subjective opinion of water quality experts and policymaker (Sutadian et al., 2016). However, there have been two methods are commonly used for weight assigning i.e. Delphi method (Abbasi and Arya, 2000) and the analytical hierarchy process (AHP; Crude 2001). The Delphi method is mostly used in various WQI for assigning the parameters weight by summing of expert opinion for minimizing subjectivity and enhance reliability. In this method, a temporary weight of highest significance rating i.e. 1.0 is assigned to the parameters and another temporary weight of parameter is obtained by dividing the highest rating i.e. 1.0 by the individual parameter mean rating i.e. the standard value of the parameters prescribed by the agencies such as WHO, BIS and many others. After that, each temporary weight of parameter is dividing by the summing of all parameters temporary weight for obtaining the final relative weight. It should be noticed that the sum of the selected parameters relative weight is 1.0 in mostly water quality index. The most used equation for calculating the relative weight as per Delphi method is given below (Brown et al., 1970):

$W_{n}=K / V_{s}$

Where, $\mathrm{W}_{\mathrm{n}}$ : relative weight, $K$ : proportion constant, $V_{s}$ : parameters standard. The value of $K$ is obtained by the given equation

$K=1 /\left(\Sigma 1 / V_{s}\right)$

Where K: proportion constant; $\mathrm{V}_{\mathrm{s}}$ : parameters standard; 1: highest significance rating. Moreover, another method for assigning the weight of the parameters is the analytical hierarchy process (AHP). The AHP is an easy concept to assign the parameters weight and also allows the developers to incorporate the qualitative and quantitative aspect. In this method, the weight assigned through pairwise matrices, and also a responding group i.e. experts or public is required for giving their suggestion (Gazzaz et al., 2012) and also it can be useful to determine the relative weight of individuals or aggregated parameters (Ocampo-Duque et al., 2006; Sutadian et al., 2016).

\section{Sub-indices aggregation for the final index score}

This is the final step of a WQI which is performed for obtaining the final index value. The final index value is obtaining by sub-indices aggregation. For aggregation, mostly three methods are used i.e. 
Additive aggregation method, Multiplicative aggregation method and logical aggregation method.

\section{Additive aggregation method}

The additive aggregation method is the most off-used method in which we combined the transform value of parameters through summation. In this method, commonly three types of sum index are applied such as linear sum index, weighted sum index and root sum index described in Table 3. The additive aggregation method is used by Horton (1965), Brown et al. (1970) and Prati et al. (1971) in their WQI.

- Linear sum index: The linear sum index is commonly used in that condition when the addition of unweighted sub-index not raised to power than 1 . The advantage of the linear sum index is the out -weighted and the disadvantage is the resulting of the poor water quality if one individual parameter is exceeding an acceptable level.

- Weighted sum index: The weighted sum index is mostly used index. The disadvantage of this index is eclipsing. The eclipsing means when the one parameter sub-index is higher than the acceptable limit then it reflects the poor water quality.

- Root sum power index: It is formed by using the non-linear aggregation function. The p-value shows the positive real number which is always greater than 1 . The ambiguous region is smaller when $p$ becomes large. This index is good for aggregation indices because it not required eclipsing region as well as the ambiguous region.

\section{Multiplicative aggregation method:}

In this method, the sub-indices are computed using product operation or geometric mean. The common multiplicative method is the weighted product. The equation of the weighted product is given below:

$I=\left[\prod_{i=1}^{n} I_{i}^{w i}\right]$

Table 3. Commonly used index in the additive aggregation method (Abbasi and Abbasi, 2012).

\begin{tabular}{lll}
\hline Index & Equation & Remark \\
\hline Linear sum index & $I=\sum_{i=1}^{n} \mathrm{I}_{i}$ & $I_{i}:$ sub-index \\
Weighted sum index & $I=\sum_{i=1}^{n} W_{i} \mathrm{I}_{i}$ & $i, n:$ number of parameters \\
& $I_{i}:$ sub-index \\
& $i, n:$ number of parameters \\
& $W_{i}:$ weight of the $i^{\text {th }}$ parameters \\
Root sum power index & $I=\left[\sum_{i=1}^{n} \mathrm{I}_{i}\right]^{1 / p}$ & $I_{i}:$ sub-index \\
& & $i, n:$ number of parameters \\
& $p:$ positive real number i.e. $>1$ \\
\hline
\end{tabular}


The disadvantage of this index is that if one sub-indices is zero, then the final index also zero and create the eclipsing condition. So, the geometric mean is used in the weighted product aggregation method using the equation:

$I=\left[\prod_{i=1}^{n} I_{i}^{g i}\right]^{1 / \gamma}$

Where $\gamma: \sum_{i=1}^{n} g_{i}$

The multiplicative aggregation method used by Landwehr et al. (1974); Walski and Parker (1974); Bhargava (1985) in their WQI.

\section{Logical aggregation method:}

This aggregation method is based combination of sub-indices using logical operation. In the logical operation, two factors are used i.e. maximum and minimum operator index. The logical index is used by Smith (1990).

- Maximum operator index : This index is performed when the root sum power index i.e. $\mathrm{p}$ approaches infinity. The general equation is: $I=\max \left(I_{1}, I_{2}, I_{3}, I_{4} \ldots I_{n}\right)$; Where $I$ : largest of sub-indices, if $I_{1}=0$, then $I=0$. This index is ideally performed when one recommended limit is violated. The disadvantage of the index is that when fine gradations become apparent then the discrete events and also some sub-indices are to be aggregated.

- Minimum operator index: This index is performed when summing of sub-indices scale is decreased while the scale of maximum operator index increases. It is the good index method for performing the decrease aggregating scale of sub-indices. The general equation is: $I=\min \left(I_{1}, I_{2}, I_{3}\right.$, $\left.I_{4} \ldots I_{n}\right)$.

\section{Most commonly used water quality indices}

From the mid-1960s to till date, a total of 33 water quality index are developed, who show the quality of a water body. In the present study, only the 7 most popular water quality index are discussed that illustrated in Table 4. These 7 WQI are selected based on their higher frequency number in most of the water quality papers. Besides, in this section, we discussed all 7 WQI and their selected parameters, sub -indices scale, parameter weight, final index equation, and also discussed the advantage and disadvantages. 


\section{National Sanitization Foundation index}

The National Sanitization Foundation (NSF) water quality index is developed by Brown et al. (1970). The modified version of this index has been applied in various countries such as India, Iran, Brazil, USA and many other countries (Effendi et al., 2015; Misaghi et al., 2017).

Parameters selection: In this index using the Delphi method a set of 11 parameters including physico-chemical parameters (8 parameters), micro-biological (1 parameter), pesticides and toxic elements are finalized (Table 4).

Sub-indices formation: In NSF WQI, Delphi technique is used to transform the selected parameters into a sub-indices scale. In this index, the formation of sub-indices of 9 parameters such as physico-chemical and microbial parameters is done using Delphi technique to produce the average curve. The sub-indices scaling of pesticides and the toxic element is formed using the categorical scaling of 0 and 1 (Sutadian et al., 2016). In most cases, only 9 parameters are selected for the study, because the other two parameters showed the eclipsing if the range is exceeding from the permissible limit. In that case, water quality directly registered as the worst condition.

Assigning weight of parameters: The unit weight of parameters has been assigned using the Delphi technique. The weight of the parameters is unequal but the sum of all parameters weight is 1 . The name of parameters and their final relative weight as follows; dissolved oxygen (0.17), $\mathrm{pH}(0.11)$, biochemical oxygen demand $(0.11)$, faecal coliform $(0.16)$, water temperature $(0.10)$, total phosphorus $(0.10)$, nitrate (0.10), turbidity (0.08) and total solids (0.07) respectively.

Aggregation for final index: In NSF WQI, generally, arithmetic or additive aggregation method is used (Brown et al., 1970). The general equation used for the NSF WQI calculation is given below:

$$
I=\sum_{i=1}^{n} w_{i} \mathrm{q}_{i}
$$

Where, $\mathrm{w}_{\mathrm{i}}$ : relative weight of the $\mathrm{i}^{\text {th }}$ parameters, $\mathrm{q}_{\mathrm{i}}$ : sub-indices quality ratings of the $i^{\text {th }}$ parameters. Besides, Brown et al. (1973) proposed NSF WQI in which they used the Multiplicative aggregation method using the following equation:

$$
I=\left[\prod_{i=1}^{n} S_{i}^{w i}\right]
$$

The purpose of using the multiplicative aggregation method is to decrease the uncertainty which is generated by a single bed parameter which directly affects the water quality. After calculated the index value, Brown et al. (1970) expressed index values ranged from 0 (very bad) to 100 (excellent) for the water quality illustrated in Table 4. Besides, Phadatare and Gawande (2016) also describe the category and colour for all the ranges that show the water quality. The following NSF WQI range status with category and colour (in brackets) are as follows such as excellent (A, Blue), good (B, green), regular (c, 
yellow), bad (D, Orange), and very bed (E, Red) respectively.

Advantages of the NSF WQI: The index is easy to understand and easily calculated. The index showing the water quality in a good manner. The index used for evaluating the water quality of different areas.

Disadvantages of the NSF WQI: The index represents only water quality, it does not represent the specific use of water. If one parameter of toxicity and pesticides parameters is exceeding than it showed the worst water quality. Due to this, the uncertainty and subjectivity is increase.

\section{Canadian Council of Ministers of the Environment water quality index}

Canadian Council of Ministers of the Environment Water Quality Index (CCME WQI) is developed by the Canadian ministry of the environment in 2001 (CCME, 2001). The CCME- WQI used as a tool to assess the water quality status of river basins, metal mines and evaluation of drinking water quality and also it provided the report of water quality status information to management institutions, policymaker, and the public (Lumb et al., 2011; Hurley et al., 2012). This index has been applied in Canada (Abbasi and Abbasi, 2012) and also applied in various countries such as India, Iran, Chile, Spain and many other countries (Espejo et al., 2012; Mostafaei, 2014; Wagh et al., 2017; Ahmed et al., 2019).

Parameters selection: In CCME WQI, the selection of parameters in this index depends on the users due to its flexibility. The user selects the parameters based on local condition and their issues. For example, in two state i.e. New Brunswick state and the Alberta state of Canada, different parameters such as 14 parameters used in New Brunswick state and Alberta state parameters are categorised in four groups mainly metals (22 parameters), pesticides (17 parameters), nutrients (6 parameters) and microbial (2 parameters) respectively (Sutadian et al., 2016).

Sub-indices formation: In this index, the sub-indices formation is not used.

Assigning of parameters weight: There is no need for establishing the parameters weight because the sub-indices formation is not used.

Aggregation of final Index: The final index of CCME WQI is based on the three factors such as scope, frequency, and amplitude which are adopted from BCWQI. These three factors create a scale from 0 to 100 for showing the water quality. The three factors that used in the development of CCME WQI final index are as follows:

- Scope: The scope is denoted by the $\mathrm{F}_{1}$ and it defines as the parameters which do not meet the water quality standards during the period of interest. The scope is calculated by using the given equation: $F_{1}=[($ number of failed variables $) /($ total number of variables $)] \times 100$

- Frequency: Frequency is denoted by $F_{2}$ and it defines as the individuals which do not meet the objective during the period of interest. It is calculated by using the given equation: $F_{2}=[$ (number of failed tests)/(total number of tests) $] \times 100$ 
- Amplitude: This step is different from the previous steps. It is denoted by the $\mathrm{F}_{3}$ and it defines as amount of failed test which does not meet their objectives. $F_{3}$ is calculated in three steps are as follows:

\section{First step:}

Ist step is the excursion that is referred to as the number of times by which an individual concentration is higher than the objectives and calculated using the equation:

excursion $_{i}=[($ failed test value i/objective $j)]-1$

Besides, another condition is that when test value must not fall below the objective, then ex-

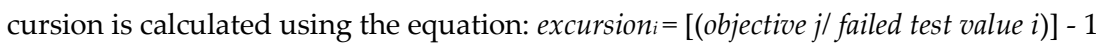

\section{Second step:}

In this step, we calculated the normalised sum of excursions that refers to the summing of excursion of the individual test from their objectives and dividing by the total number of tests including a test that meets and do not meet their objectives (Abbasi and Abbasi, 2012). The normalised sum of excursions is calculated by the given equation:

$n s e=\frac{\sum_{i}^{n} \text { excursion }_{i}}{\text { total number of test (including meet and do not meet their objectives) }}$

\section{Third step:}

In this step, we calculated $\mathrm{F}_{3}$, using the asymptotic function that provides a scale from 0 to 100 by scales the nse (normalised sum of excursions) using the equation given below:

$F_{3}=[(\mathrm{nse} / 0.01 \mathrm{nse}+0.01)]$

\section{Final equation of CCME WQI:}

CCME WQI $=100-\left(\frac{\sqrt{F_{1}^{2}+F_{2}^{2}+F_{3}^{2}}}{1.732}\right)$

In the equation, 1.732 factor is used to minimize the vector length as maximum to 100 . The rank scale of CCME-WQI ranged 0 i.e. very bad to 100 i.e. excellent water quality are described in Table 4.

Advantages of the CCME WQI: The index is easy to understand and easily calculated. In this index, we do not calculate the sub-indices and parameters weight. The index represents both water quality and specific use of water.

Disadvantages of the CCME WQI: In this index, minimum of 4 parameters are required for assessing the water quality status. A maximum number of parameters is not satisfied.

\section{Bhargava water quality index}

It is the first reported index which developed by an Asian scientist namely D.S. Bhargava in 1983 


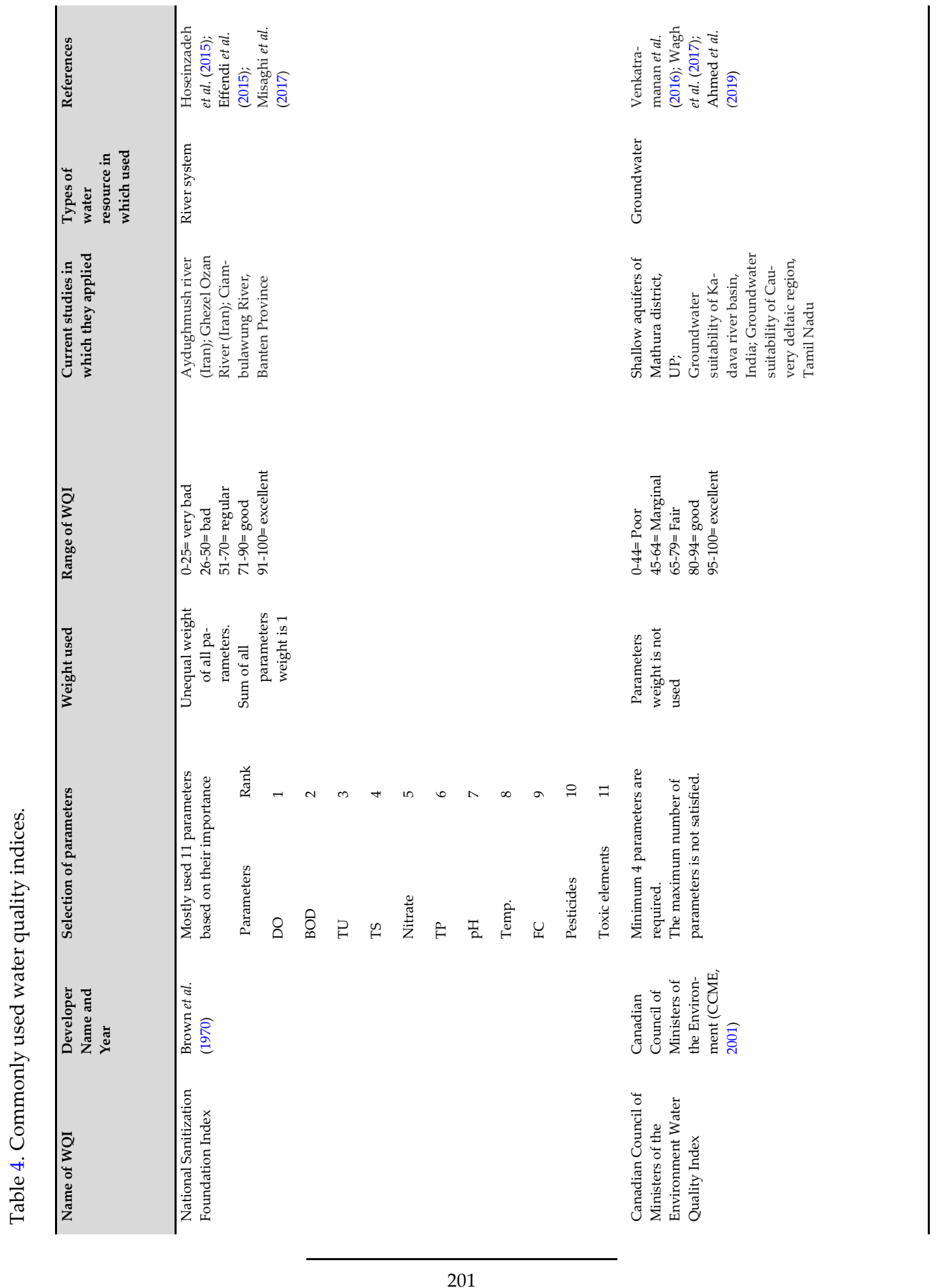




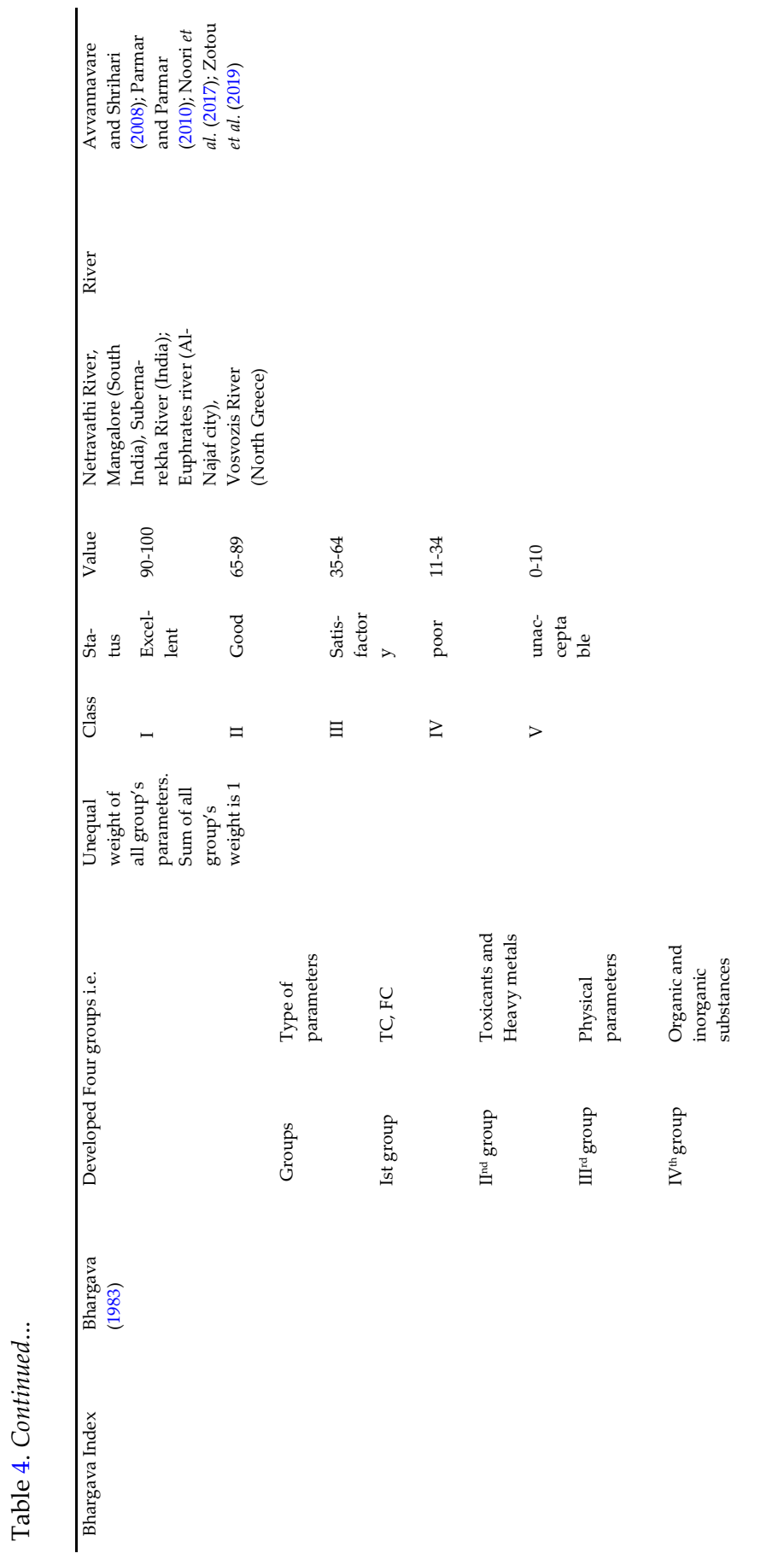

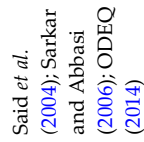

苋

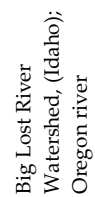

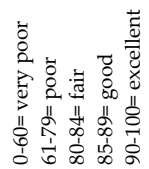

$\frac{7}{5}$
$\frac{7}{80}$
3
$\frac{5}{5}$
$\frac{5}{9}$

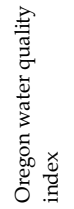




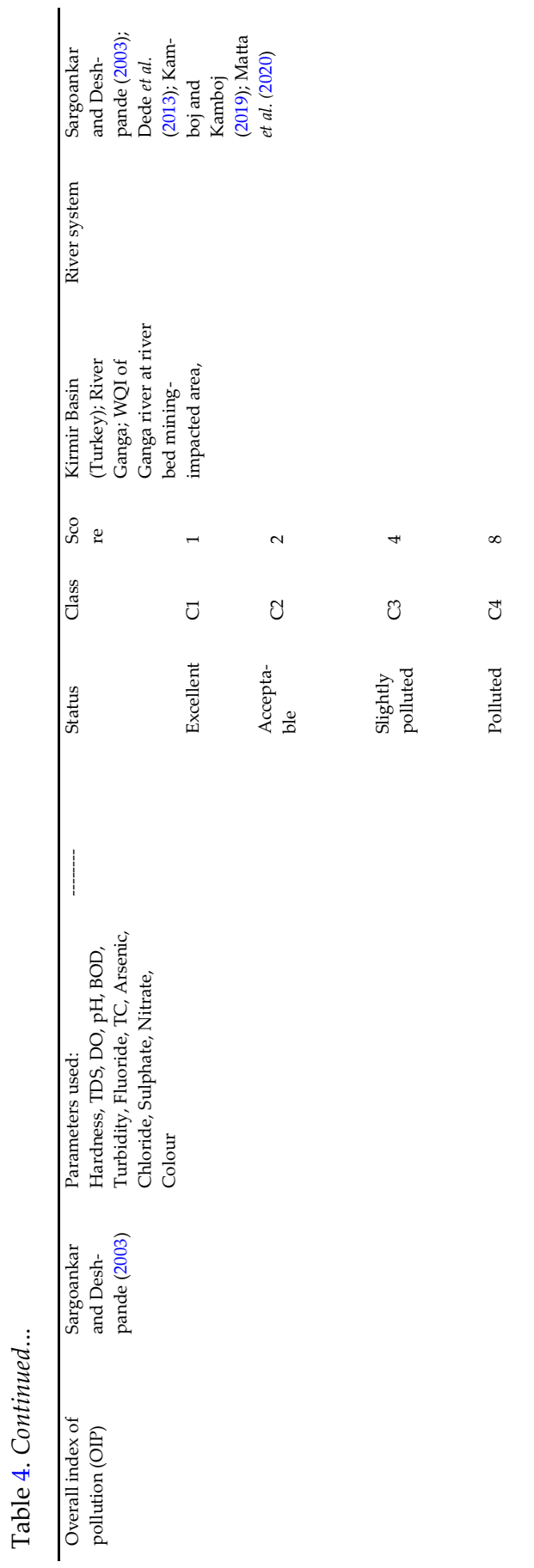

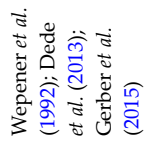

$\stackrel{\grave{d}}{\grave{a}}$
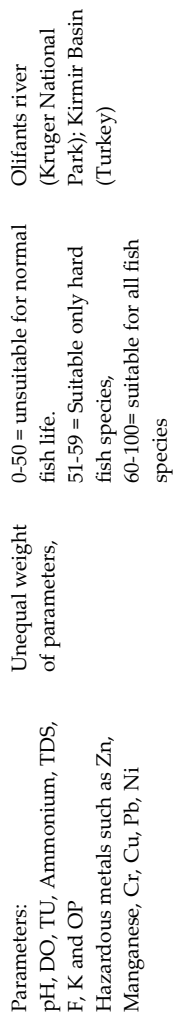

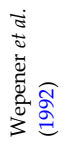

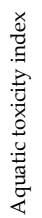

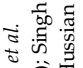

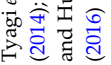

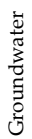

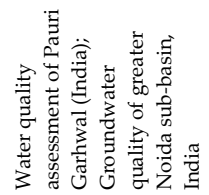

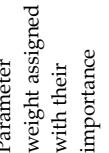
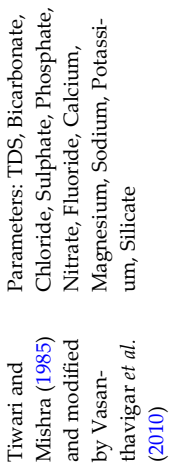
(Bhargava, 1983; Abbasi and Abbasi, 2012). This index is commonly used to assess the drinking water supply, suitability of surface water for drinking. This index has been applied by a various researcher in various country or region such as India (Avvannavare and Shrihari, 2008; Parmar and Parmar, 2010), Al-Najaf city (Noori et al., 2017), and Zotou et al. (2019).

Parameters selection: In this index, 4 groups of parameters were selected. The groups and types of parameters used are illustrated in Table 4. In ist group, microbial parameters such as TC, FC are selected for assessing the drinking water quality. In the $2^{\text {nd }}$ group, toxic and heavy metals parameters are selected while in $3^{\text {rd }}$ and $4^{\text {th }}$ groups physical and inorganic or organic parameters were being studied respectively.

Sub-indices formation: The formation of sub-indices in the index is developed by a different equation. Each group parameters are transferred on a common scale by using the equation illustrated in Table 5 . Assigning weight of parameters: In this index, the weight of the selected parameter is different but the sum of all parameters weight is equal to 1.

Aggregation of final Index: In this index, the final index value is based on the multiplicative aggregation method i.e. geometric mean. The general equation used for the Bhargava WQI calculation is given below:

$C C M E W Q I=100-\left(\frac{\sqrt{F_{1}^{2}+F_{2}^{2}+F_{3}^{2}}}{1.732}\right)$

Where, $f_{i}\left(P_{i}\right)$ : sensitive function includes weighting of the of $\mathrm{i}^{\text {th }}$ variables, $\mathrm{n}$ : number of variables consider. After calculated final index value, the Bhargava WQI categorised the water quality in five groups with their status and rank value are illustrated in Table 4.

Advantages of the Bhargava WQI: The index is easy to understand and easily calculated. The index represents both water quality and specific use of water.

Disadvantages of the Bhargava WQI: The number of the parameter is defined, so in this index, we can only calculate the water quality status based on these parameters.

Table 5. Sub-indices equation used in Bhargava Index (Abbasi and Abbasi, 2012).

\begin{tabular}{lll}
\hline Groups & Sub-indices equation & CMCL \\
\hline${ }^{\text {st }}$ group & $f_{1}=\exp [-16(C-1)]$ & Coliform bacteria $/ 100 \mathrm{ml}$ \\
$\mathrm{II}^{\text {nd }}$ group & $f_{1}=\exp [-4(C-1)]$ & $0.05 \mathrm{mg} / \mathrm{L}$ each \\
IIIId $^{\text {rd }}$ group & $f_{1}=\exp [-2(C-1)]$ & $1 \mathrm{TU} 15$ colour unit \\
$\mathrm{IV}^{\text {th }}$ group & $f_{1}=\exp [-2(C-1)]$ & $250 \mathrm{mg} / \mathrm{L}$ each \\
\hline
\end{tabular}




\section{Oregon water quality index}

The Oregon water quality index is developed by the Oregon department of environmental quality in 1970 and then it modified or updated by the C.G. Cude in 2001 (Abbasi and Abbasi, 2012). The purpose of this index is the summarizing and calculation of the water quality status of rivers in Oregon. This index is mostly used by the Oregon department of environmental quality and also used by the Idaho department of environmental quality (IDEQ, 2002; ODEQ, 2014; Sutadian et al., 2016). This index is also a part of WQI software namely QUALIDEX (Sutadian et al., 2016).

Parameters selection: In this index, a total of 8 parameters such as dissolved oxygen, faecal coliform, biological oxygen demand, $\mathrm{pH}$, total solids, total phosphorus, ammoniacal nitrate, temperature, are used. The purpose behind the selection of these parameters is the better understanding and the significant importance in water quality status.

Sub-indices formation: The formation of sub-indices in Oregon WQI is developed by using the non-linear regression curve for six parameters such as dissolved oxygen, biological oxygen demand, $\mathrm{pH}$, total solids, and Ammonical nitrate (Cude, 2001). The rating curve for total phosphorus and temperature was developed by assessing the eutrophication condition of Oregon's stream and protection of the cold water fisheries respectively (Sutadian et al., 2016).

Assigning weight of parameters: For assigning the parameter weight, Delphi technique is used. In the Oregon index, equal-weighted parameters are used. The parameter weight of six parameters are dissolved oxygen (0.4), faecal coliform (0.2) and weight of other parameters such as ammonical nitrate, $\mathrm{pH}$, total solids and biological oxygen demand is 0.1 .

Aggregation of final index: Previously in this index, the additive method is used for generating the final index value. But in the modified version of Oregon index (Cude, 2001), the unweighted harmonic square formula is used for finding the final index value. The general equation of the index is given below:

$$
W Q I=\left[\prod_{i=1}^{n} f_{i}\left(P_{i}\right)\right]^{\frac{1}{n}} \times 100
$$

The interpretation of the final index value is categorised in five classes such as very poor class lies when index value ranges from 0 to 60 , poor when index value ranges from 61 to 79 , fair when index value ranges from 80 to 84 , good when index value ranges from 85 to 89 , excellent when index value ranges from 90 to 100 .

Advantages of the Oregon WQI: This is the best method for assessing the effectiveness of water quality activities. We can also develop an environmental indicator for finding the percentage of sites with good water quality or not.

Disadvantages of the Oregon WQI: Mostly this method is developed and applied only the Oregon river system. 
For adding the total phosphorus in Oregon WQI, firstly we assess the eutrophication condition of the water body.

\section{Overall Index of Pollution WQI}

The index is developed by the Sargoankar and Deshpande (2003) for assessing the surface water quality in Indian condition. In this method, a classification criterion was developed that is based on the standard providing by the water quality standards agencies such as world health organization (WHO), Bureau of Indian Standards (BIS), Central pollution control board (CPCB), European Community (EC). This method demonstrated the effect of pollution on water quality parameters. This method is applied in Indian rivers such as river Ganga (Kamboj and Kamboj, 2019; Matta et al., 2020), Yamuna river (Sargoankar and Deshpande, 2003) and Kirmir Basin, Turkey (Dede et al., 2013) for assessing the water quality status.

Parameters selection: Sargoankar and Deshpande (2003) selected a total of 13 parameters such as $\mathrm{pH}$, turbidity, colour, total dissolved solids, dissolved oxygen, biological oxygen demand, hardness, chloride, nitrate, sulphate, total coliform, arsenic and fluoride. These parameters are the key indicator parameters to assess the surface water quality and its deterioration due to the pollution activity.

Sub-indices formation: In the OIP index, the formation of the sub-indices is developed by the concentration of the particular parameter. For each parameter, a mathematical equation is developed according to their concentration illustrated in Table 6.

Assigning weight of parameters: In the OIP, there is no weight assigned for the parameter.

Aggregation of final index: For obtained the final index value, the general equation is used to assess the overall index of pollution is:

$$
W Q I=\sqrt{\frac{n}{\sum_{i=1}^{n} \frac{1}{S l_{i}^{2}}}}
$$

Where $n$ is the total number of parameters, $P_{i}$ is the pollution indices of the $i$ th parameters. The calculation of $P_{i}$ based on the sub-indices mathematical equation that is illustrated in Table 6. In OIP, the interpretation of the final index value is based on the classification, class and index score of the particular parameters.

Advantages of the OIP index: This index indicates the responsible parameters that deteriorate the water quality of the water body. This tool used as formulating the pollution strategies in different areas of the water body. This index is easiest and simply understand to assess the water quality status. 
Table 6. Sub-indices equation and classification of water quality index of overall index of pollution (Sargaonkar and Deshpande, 2003)

\begin{tabular}{|c|c|c|c|c|c|c|c|}
\hline \multirow[t]{7}{*}{ Parameters } & \multirow[t]{7}{*}{ Range } & \multirow[t]{7}{*}{ Mathematical equation } & \multicolumn{5}{|c|}{ Classification } \\
\hline & & & $\begin{array}{l}\text { Excel- } \\
\text { lent }\end{array}$ & Acceptable & $\begin{array}{l}\text { Slightly } \\
\text { Polluted }\end{array}$ & $\begin{array}{l}\text { Pollut- } \\
\text { ed }\end{array}$ & $\begin{array}{l}\text { Heavily } \\
\text { Polluted }\end{array}$ \\
\hline & & & \multicolumn{5}{|l|}{ Class } \\
\hline & & & $\mathrm{C} 1$ & $\mathrm{C} 2$ & $\mathrm{C} 3$ & C4 & C5 \\
\hline & & & \multicolumn{5}{|c|}{ Index Score } \\
\hline & & & 1 & 2 & 4 & 8 & 16 \\
\hline & & & \multicolumn{5}{|c|}{ Concentration range/limit } \\
\hline \multirow[t]{3}{*}{$\mathrm{pH}$} & 7 & $x=1$ & $6.5-7.5$ & $6.0-6.5$ and & $5.0-6.0$ and & $4.5-5$ & $<4.5$ and \\
\hline & $>7$ & $x=\exp ((y-7.0) / 1.082)$ & & $7.5-8.0$ & $8.0-9.0$ & and 9- & $>9.5$ \\
\hline & $<7$ & $x=\exp ((7.0-y) / 1.082)$ & & & & & \\
\hline \multirow{3}{*}{$\begin{array}{l}\text { Turbidity } \\
\text { (NTU) }\end{array}$} & $\leq 5$ & $x=1$ & 5 & 10 & 100 & 250 & $>250$ \\
\hline & $5-10$ & $\mathrm{x}=(\mathrm{y} / 5)$ & & & & & \\
\hline & $10-500$ & $x=(y+43.9) / 34.5$ & & & & & \\
\hline \multirow{2}{*}{$\begin{array}{l}\text { Colour } \\
\text { (Hazen) }\end{array}$} & $10-150$ & $x=(y+130) / 140$ & 10 & 150 & 300 & 600 & 1200 \\
\hline & $150-1200$ & $x=(y / 75)$ & & & & & \\
\hline \multirow[t]{3}{*}{$\mathrm{DO}(\%)$} & $<50$ & $x=\exp (-(y-98.33) / 36.067)$ & $88-112$ & $75-125$ & $50-150$ & $20-200$ & $\begin{array}{l}<20 \text { and } \\
>200\end{array}$ \\
\hline & $50-100$ & $x=(y-107.58) / 14.667$ & & & & & \\
\hline & $\geq 100$ & $x=(y-79.543) / 19.054$ & & & & & \\
\hline \multirow[t]{2}{*}{ BOD (mg/L) } & $<2$ & $x=1$ & 1.5 & 3 & 6 & 12 & 24 \\
\hline & $2-30$ & $x=y / 1.5$ & & & & & \\
\hline \multirow[t]{4}{*}{ TDS (mg/L) } & $\leq 500$ & $x=1$ & 500 & 1500 & 2100 & 3000 & $>3000$ \\
\hline & $500-1500$ & $x=\exp ((y-500) / 721.5)$ & & & & & \\
\hline & $1500-3000$ & $x=(y-1000) / 125$ & & & & & \\
\hline & $3000-6000$ & $x=y / 375$ & & & & & \\
\hline \multirow{3}{*}{$\begin{array}{l}\text { Hardness as } \\
\mathrm{CaCO}_{3}(\mathrm{mg} / \mathrm{L})\end{array}$} & $\leq 75$ & $x=1$ & 75 & 150 & 300 & 500 & $>500$ \\
\hline & $75-500$ & $x=\exp (y+42.5) / 205.58$ & & & & & \\
\hline & $>500$ & $x=(y+500) / 125$ & & & & & \\
\hline \multirow{3}{*}{$\begin{array}{l}\text { Chloride (mg/ } \\
\text { L) }\end{array}$} & $\leq 150$ & $x=1$ & 150 & 250 & 600 & 800 & $>800$ \\
\hline & $150-250$ & $x=\exp ((y / 50)-3) / 1.4427)$ & & & & & \\
\hline & $>250$ & $x=\exp ((y / 50)+10.167) / 10.82$ & & & & & \\
\hline \multirow[t]{3}{*}{$\mathrm{NO}_{3}(\mathrm{mg} / \mathrm{L})$} & $\leq 20$ & $x=1$ & 20 & 45 & 50 & 100 & 200 \\
\hline & $20-50$ & $x=\exp ((y-145.16) / 76.28)$ & & & & & \\
\hline & $50-200$ & $x=y / 65$ & & & & & \\
\hline \multirow[t]{2}{*}{$\mathrm{SO}_{4}(\mathrm{mg} / \mathrm{L})$} & $\leq 150$ & $x=1$ & 150 & 250 & 400 & 1000 & $>1000$ \\
\hline & $150-2000$ & $\mathrm{x}=((\mathrm{y} / 50)+0.375) / 2.5121$ & & & & & \\
\hline \multirow{4}{*}{$\begin{array}{l}\text { Total coliform } \\
\text { (MPN) }\end{array}$} & $\leq 50$ & $x=1$ & 50 & 500 & 5000 & 10000 & 15000 \\
\hline & $50-5000$ & $\mathrm{x}=(\mathrm{y} / 50)^{* *} 0.30110$ & & & & & \\
\hline & $5000-15000$ & $x=((y / 50)-50) / 16.071$ & & & & & \\
\hline & $>15000$ & $x=(y / 15000)+16$ & & & & & \\
\hline \multirow[t]{4}{*}{ As (mg/L) } & $\leq 0.005$ & $x=1$ & 0.005 & 0.01 & 0.05 & 0.1 & 1.3 \\
\hline & $0.005-0.01$ & $x=y / 0.005$ & & & & & \\
\hline & $0.01-0.1$ & $x=(y+0.015) / 0.0146$ & & & & & \\
\hline & $0.1-1.3$ & $x=(y+1.1) / 0.15$ & & & & & \\
\hline \multirow[t]{2}{*}{$\mathrm{F}(\mathrm{mg} / \mathrm{L})$} & $0-1.2$ & $x=1$ & 1.2 & 1.5 & 2.5 & 6.0 & $>6.0$ \\
\hline & $1.2-10$ & $x=((y / 1.2)-0.3819) / 0.5083$ & & & & & \\
\hline
\end{tabular}




\section{Aquatic toxicity index}

The aquatic toxicity index is proposed by Wepener et al. (1992) to assess the effect of water quality on the aquatic organisms especially fish fauna. The ATI showed the health status of the aquatic ecosystem that is better of aquatic organisms or not based on their water quality health status. The aquatic toxicity index is applied widely to assess the suitability and health status of the aquatic ecosystem (Dede et al., 2013; Gerber et al., 2015).

Parameter selection: In the ATI, the selection criteria for the parameter is based on their role and importance for the survival of the aquatic organisms. In this index, a total of 14 water quality parameter that is the combination of 8 physico-chemical parameters such as $\mathrm{pH}$, turbidity, total dissolved solids, dissolved oxygen, ammonia, orthophosphate, fluoride and Potassium while 6 hazardous or toxic metals such as manganese, copper, lead, nickel, zinc and chromium (Table 4).

Sub-indices formation: The formation of the sub-indices curve was developed based on the smith index. The equation used for transforming the parameters on a common scale for determining the index rating values is illustrated in Table 7 .

Assigning weight of parameters: There is no need for assigning the parameters weight.

Aggregation of final index: In ATI water quality index, the aggregation of the final index is applied using the unweighted additive aggregation function method.

Table 7. Equation used for developing the sub-indices curve in aquatic toxicity index (Wepener et al., 1992).

\begin{tabular}{ll}
\hline Parameter & Mathematical equation \\
\hline $\mathrm{pH}$ & $\mathrm{Y}=98 \exp \left[-(\mathrm{pH}-8.16)^{2}(0.4)\right]+17 \exp \left[-(\mathrm{pH}-5.2)^{2}(0.5)\right]+15 \exp [-(\mathrm{pH}-11)$ \\
& $2(0.72)]+2$ \\
Dissolved oxygen & $0 \leq \mathrm{DO} \leq 5 ; \mathrm{y}=10(\mathrm{DO})$ \\
& $5<\mathrm{DO} \leq 6 ; \mathrm{y}=20(\mathrm{DO})-50$ \\
& $6<\mathrm{DO} \leq 9 ; \mathrm{y}=10(\mathrm{DO})+10$ \\
& Do $>9 ; \mathrm{y}=100$ \\
& $0.02 \leq \mathrm{NH}_{4} ; \mathrm{y}=100$ \\
Ammonium & $0.02<\mathrm{NH}_{4}{ }^{+} \leq 0.062 ; \mathrm{y}=-500\left(\mathrm{NH}_{4}+\right)+110$ \\
& $0.062<\mathrm{NH}_{4}+\leq 0.5 ; \mathrm{y}=40\left(\mathrm{NH}_{4}+0.65\right)^{2}$ \\
& $\mathrm{NH} 4^{+}>0.5 ; \mathrm{y}=-5.8\left(\mathrm{NH}_{4}+\right)+32.5$ \\
Turbidity & $\mathrm{Y}=-220 \ln (0.001 \ln (\mathrm{NTU})+30)+689$ \\
Total dissolved solids & $\mathrm{Y}=117 \exp -0.00068(\mathrm{TDS})-7$ \\
Potassium & $\mathrm{Y}=150 \exp -0.02(\mathrm{~K})-8$ \\
Orthophosphate & $\mathrm{Y}=100 \exp (\mathrm{P})(-2.4)$ \\
Manganese & $\mathrm{Y}=0.115 \exp \mathrm{p}^{-0.05} \mathrm{exp}(\mathrm{Mnn}) .0013+5$ \\
Nickel & $\mathrm{Y}=28 \ln (1(\mathrm{Ni}+10))+211$ \\
Fluoride & $\mathrm{Y}=-71 \ln (0.001(\mathrm{~F}+2.5))+235$ \\
Chromium & $\mathrm{Y}=-40 \ln (0.1(\mathrm{Cr}+150))+210$ \\
Lead & $\mathrm{Y}=-30 \ln (0.1(\mathrm{~Pb}+30))+148$ \\
Copper & $\mathrm{Y}=-26 \ln (1(\mathrm{Cu}+18))+180$ \\
Zinc & $\mathrm{Y}=-22 \ln (0.001(\mathrm{Zn}-20))+16$ \\
\hline
\end{tabular}


The general formula for calculating the ATI as follows:

$$
A T I=\frac{1}{100}\left(\frac{1}{n} \sum_{i=1}^{n} q_{i}\right)^{2}
$$

Where $\mathrm{n}$ is the number of parameters, $\mathrm{q}_{\mathrm{i}}$ is the sub-indices of parameters. The interpretation of ATI water quality index is displayed in Table 4.

Advantages of the ATI index: This index is very useful to assess the water quality is suitable for aquatic organisms or not. It also showed the responsible water parameter that affects water quality.

\section{Groundwater quality assessment index}

The groundwater quality assessment index is usually used for assessing groundwater quality (Tiwari and Mishra, 1985). In India, for assessing the groundwater quality, the WQI of Tiwari and Mishra (1985) is used. But this index is not specific groundwater quality index. But some researcher such as Vasanthavigar et al. (2010) modified the WQI of Tiwari and Mishra for assessing the groundwater quality (Abbasi and Abbasi, 2012). This index is used widely in India for assessing the groundwater quality status (Tyagi et al., 2014; Singh and Hussian, 2016).

Parameter selection: In WQI of Tiwari and Mishra, selection of parameter based on the experience and indicated parameters are selected. But the modified groundwater quality index (Vasanthavigar et al., 2010), a total of 12 parameters has been selected based on their importance (illustrated in Table 4).

Sub-indices formation: In this index, the quality rating scale is developed by dividing the concentration of parameters with their standard limits. The formula used for rating the parameters as follows:

$$
q_{i}=\left(\frac{C_{i}}{S_{i}}\right) \times 100
$$

Where, qi: quality scale of ith parameters, $C_{i}$ : actual concentration of the ith parameters, $S_{i}$ : Standard value of $i$ th parameters given by BIS and WHO.

Assigning weight of parameters: In this index, the weight of the parameter is assigned based on their importance in the water quality. The maximum weight of parameters are assigned 5 and minimum are assigned 1. Firstly, we assigned the parameter weight and then we calculated the relative weight of the parameter (illustrated in Table 7) by the given formula.

$W_{i}=w_{i} / \sum_{i=1}^{n} w_{i}$ 
Where, $\mathrm{W}_{\mathrm{i}}$ : relative weight of ith parameters; $\mathrm{w}_{\mathrm{i}}$ : assigned weight of the ith parameter.

Aggregation of final index: The aggregation of the final index value is generally assessed by the given formula:

$\mathrm{WQI}=\sum S I_{i}$

Where $S I_{i}$ is the sub-index value of ith parameters and can be calculated using the equation:

$S I_{i}=W_{i} \times q_{i}$

Where, $W_{i}$ : relative weight of ith parameters; $Q_{i}$ : quality rating scale of ith parameters; The interpretation of the groundwater quality index is illustrated in Table 8.

Advantages of the groundwater quality index: This index is a useful tool to assess groundwater quality. It also suggests the suitability of groundwater for drinking and irrigation purpose. It also showed the responsible water parameter that affects groundwater quality.

\section{Conclusion and recommendation}

The present chapter focusses on the water quality index tool that is used for assessing the water quality of any water body for their suitability condition for humans as well as aquatic organisms, and also suggests the uses of water in various work. In this chapter, we discussed the basic four steps that are used in the development of a WQI such as the selection of parameters, sub-indices formation, parameter weight and aggregation of the final index.

Table 8. Assigning the parameters weight according to BIS (2012) and WHO (2012) standards (Vasanthavigar et al., 2010)

\begin{tabular}{lllll}
\hline Parameters & Unit & BIS standards & Assigning weight & Relative weight \\
\hline $\mathrm{TDS}$ & $\mathrm{mg} / \mathrm{l}$ & 500 & 5 & 0.116 \\
$\mathrm{HCO}_{3}$ & $\mathrm{mg} / \mathrm{l}$ & 244 & 1 & 0.023 \\
$\mathrm{SO}_{4}$ & $\mathrm{mg} / \mathrm{l}$ & 200 & 5 & 0.116 \\
$\mathrm{PO}_{4}$ & $\mathrm{mg} / \mathrm{l}$ & - & 1 & 0.023 \\
$\mathrm{NO}_{3}$ & $\mathrm{mg} / \mathrm{l}$ & 45 & 5 & 0.116 \\
$\mathrm{~F}$ & $\mathrm{mg} / \mathrm{l}$ & 1.0 & 5 & 0.116 \\
$\mathrm{Cl}$ & $\mathrm{mg} / \mathrm{l}$ & 250 & 5 & 0.116 \\
$\mathrm{Ca}$ & $\mathrm{mg} / \mathrm{l}$ & 75 & 3 & 0.070 \\
$\mathrm{Mg}$ & $\mathrm{mg} / \mathrm{l}$ & 30 & 3 & 0.070 \\
$\mathrm{Na}$ & $\mathrm{mg} / \mathrm{l}$ & 200 & 4 & 0.093 \\
$\mathrm{~K}$ & $\mathrm{mg} / \mathrm{l}$ & - & 2 & 0.047 \\
Silicate & $\mathrm{mg} / \mathrm{l}$ & - & 2 & 0.047 \\
& & & $\sum \mathrm{w}_{\mathrm{i}}=41$ & $\sum \mathrm{W}_{\mathrm{i}}=0.953$ \\
\hline
\end{tabular}


Although, we select seven water quality index based on their popularity, used by many researchers throughout the world. These seven water quality index is discussed in detail with the selection criteria of parameters, the formation of sub-indices, assigned the parameters weight, aggregation of the final index, advantages and disadvantages. The main advantages of these water quality indices is indicated the ranking and status of the water body of any region or country. At last, we conclude that there are some restriction in these water quality indices such as selection of parameters. If we compare the water quality status of water body using two different water quality indices than we used a fixed set of parameters for both the indices.

Conflict of interest: The author declares that there is no conflict of interest.

\section{Acknowledgments}

One of the author (Vishal Kamboj) highly grateful to the Department of Science and Technology (DST), New Delhi, India for providing the financial support through INSPIRE programme (IF160805) and also thanks to the Department of Zoology and Environmental Science, Gurukula Kangri (Deemed to be University), Haridwar for providing the lab facility.

\section{References}

Abbasi, S.A. and Arya, D.S. (2000). Environmental Impact Assessment. Discovery Publishing House, New Delhi.

Abbasi, T. and Abbasi, S.A. (2012). Water quality indices. Burlington: Elsevier Science.

Ahmed, S., Khurshid, S., Madan, R., Amarah, B.A.A. and Naushad, M. (2020). Water quality assessment of shallow aquifer based on Canadian Council of Ministers of the environment index and its impact on irrigation of Mathura District, Uttar Pradesh. Journal of King Saud University-Science, 32(1): 1218-1225.

Almeida, C., González, S., Mallea, M. and González, P. (2012). A recreational water quality index using chemical, physical and microbiological parameters. Environmental Science and Pollution Research, 19(8): 3400-3411, https://doi.org/10.1007/s11356-012-0865-5.

Avvannavar, S.M. and Shrihari, S (2008). Evaluation of water quality index for drinking purposes for river Netravathi, Mangalore, South India. Environmental Monitoring and Assessment, 143: 279-290, https://doi.org/10.1007/s10661-007-9977-7

Bhargava, D.S. (1985). Water quality variations and control technology of Yamuna River. Environmental Pollution Series A: Ecological and Biological, 37(4): 355-376.

Brown, R.M., McClelland, N.I., Deininger, R.A. and Tozer, R.G. (1970). A water quality index-do we dare? Water and Sewage Works, 117(10): 339-343.

Canadian Council of Ministers of the Environment (CCME; 2001). CCME Water Quality Index 1.0 Technical Report and User's Manual. Canadian Environmental Quality Guidelines. Technical Subcommittee, Gatineau.

Choudhary, M., Pal, C. and Kamboj, N. (2014). Potable water is a serious Environmental issue: A special study on Umiam area, of RI-Bhoi District, Meghalaya, India. International Research Journal of Environmental Sciences, 3: 37-42.

Cude, C.G. (2001). Oregon water quality index a tool for evaluating water quality management effectiveness. Journal of the American Water Resources Association, 37(1): 125-137. 
Debels, P., Figueroa, R., Urrutia, R., Barra, R. and Niell, X. (2005). Evaluation of water quality in the Chillán River (central Chile) using physicochemical parameters and a modified water quality index. Environmental Monitoring and Assessment, 110(1-3): 301-322.

Dede, O.T., Telci, I.T. and Aral, M.M. (2013). The use of water quality index models for the evaluation of surface water quality: a case study for Kirmir Basin, Ankara, Turkey. Water Quality, Exposure and Health, 5(1): 41-56.

Effendi, H., Romanto, W.Y. and Wardiatno, Y. (2015). Water quality status of Ciambulawung River, Banten Province, based on pollution index and NSF-WQI. Procedia Environmental Sciences, 24(4): 228-237.

Espejo, L., Kretschmer, N., Oyarzún, J., Meza, F., Núñez, J. and Maturana, H. (2012). Application of water quality indices and analysis of the surface water quality monitoring network in semiarid North-Central Chile. Environmental Monitoring and Assessment, 184(9): 5571-5588, https://doi.org/10.1007/s10661-011-2363-5

Gazzaz, N.M., Yusoff, M.K., Aris, A.Z., Juahir, H. and Ramli, M.F. (2012). Artificial neural network modelling of the water quality index for Kinta River (Malaysia) using water quality variables as predictors. Marine Pollution Bulletin, 64(11): 2409-2420, https://doi.org/10.1016/j.marpolbul.2012.08.005

Gerber, R., Wepener, V. and Smit, N.J. (2015). Application of multivariate statistics and toxicity indices to evaluate the water quality suitability for fish of three rivers in the Kruger National Park, South Africa. African Journal of Aquatic Sciences, 40 (3): 247-259, https://doi.org/10.2989/16085914.2015.1073139

Gummadi, S., Latha, G.S., Vijayakumar, G., Rao, P.B. and Venkatarathnamma, V. (2015). Application of nemerow's pollution index (NPI) for groundwater quality assessment of bapatla mandal west region, coastal Andhra Pradesh, India. International Journal of Applied Science and Engineering Research, 4(4): 500-506.

Hanh, P.T.M., Sthiannopkao, S., Ba, D.T. and Kim, K.W. (2011). Development of water quality indexes to identify pollutants in Vietnam's surface water. Journal of Environmental Engineering, 137(4): 273-283.

Horton, R.K. (1965). An index number system for rating water quality. Journal of Water Pollution Control Federation, 37(3): 300306.

Hoseinzadeh, E., Khorsandi, H., Wei, C. and Alipour, M. (2015). Evaluation of Aydughmush river water quality using the national sanitation foundation water quality index (NSFWQI), river pollution index (RPI), and forestry water quality index (FWQI). Desalination and Water Treatment, 54(11): 2994-3002.

Hurley, T., Sadiq, R. and Mazumder, A. (2012). Adaptation and evaluation of the Canadian Council of Ministers of the Environment Water Quality Index (CCME WQI) for use as an effective tool to characterize drinking source water quality. Water Research, 46(11): 3544-3552, https://doi.org/10.1016/j.watres.2012.03.061

IDEQ, (2002). Idaho River Assessment Framework. Accessed on Sept. 2020 from https://www.deq.idaho.gov/media/457032assessment_river_entire.pdf.

Jahad, U.A. (2014). Evaluation water quality index for irrigation in the north of Hilla city by using the Canadian and Bhargava methods. Journal of University of Babylon, 22(2): 346-353.

Juwana, I., Perera, B.J.C. and Muttil, N. (2010). A water sustainability index for West Java part 2: refining the conceptual framework using Delphi technique. Water Science and Technology, 62(7): 1641-1652.

Kamboj, N. and Choudhary, M. (2013). Impact of solid waste disposal on ground water quality near Gazipur dumping site, Delhi, India. Journal of Applied and Natural Science, 5(2): 306-312.

Kamboj, N. and Kamboj, V. (2019). Water quality assessment using overall index of pollution in riverbed-mining area of Ganga-River Haridwar, India. Water Science, 33(1): 65-74, https://doi.org/10.1080/11104929.2019.1626631

Kamboj, N., Chaubey, A.K., Kumar, S. and Parasher, C.K. (2015). Quality Assessment of Municipal supplied water for drinking purpose, district Haridwar, Uttarakhand, India. Journal of Global Biosciences, 4(5): 2375-2379.

Kamboj, V. and Kamboj, N. (2020). Spatial and temporal variation of zooplankton assemblage in the mining-impacted stretch of Ganga River, Uttarakhand, India. Environmental Science and Pollution Research, 27(21): 27135-27146. 
https://doi.org/10.1007/s11356-020-09089-1

Kamboj, V., Kamboj, N. and Sharma, A.K. (2020). A review on general characteristics, classification and degradation of river systems. In: Environmental Degradation: Causes and Remediation Strategies, Volume 1, Eds. Kumar, V., Singh, J. and Kumar, P., pp. 47-62, https://doi.org/10.26832/aesa-2020-edcrs-04

Kannel, P.R., Lee, S., Lee, Y.S., Kanel, S.R. and Khan, S.P. (2007). Application of water quality indices and dissolved oxygen as indicators for river water classification and urban impact assessment. Environmental Monitoring and Assessment, 132(1-3): 93-110.

Kumar, V., Kumar, S., Srivastava, S., Singh, J. and Kumar, P. (2018). Water quality of River Ganga with reference to physicochemical and microbiological characteristics during Kanwar Mela 2017, at Haridwar, India: A case study. Archives of Agriculture and Environmental Science, 3(1): 58-63.

Landwehr, J.M., Deininger, R.A., Mcclelland, N.L. and Brown, R.M. (1974). An objective water quality index. Journal of the Water Pollution Control Federation, 46(7): 1804-1807.

Linstone, H.A. and Turoff, M. (2002). The Delphi method: techniques and applications. Addison-Wesley Publishers.

Lumb, A., Sharma, T.C., Bibeault, J.F. and Klawunn, P. (2011). A comparative study of USA and Canadian water quality index models. Water Quality, Exposure and Health, 3(3-4): 203-216, https://doi.org/10.1007/s12403-011-0056-5

Matta, G., Nayak, A., Kumar, A. and Kumar, P. (2020). Water quality assessment using NSFWQI, OIP and multivariate techniques of Ganga River system, Uttarakhand, India. Applied Water Science, 10(9): 206, https://doi.org/10.1007/s13201-020-01288-y

Misaghi, F., Delgosha, F., Razzaghmanesh, M. and Myers, B. (2017). Introducing a water quality index for assessing water for irrigation purposes: A case study of the Ghezel Ozan River. Science of the Total Environment, 589: 107-116.

Mostafaei, A. (2014). Application of multivariate statistical methods and water quality index to evaluation of water quality in the Kashkan River. Environmental Management, 53(4): 865-881, https://doi.org/10.1007/s00267-014-0238-6

Noori, M.M., Abdulrazzaq, K.A., Mohammed, A.H. (2017). Evaluation of Water Quality using Bhargava Water Quality Index Method and GIS, Case Study: Euphrates River in Al-Najaf City. International Journal of Science and Research, 6(7): 12861295. https://doi.org/10.21275/ART20175545.

Ocampo-Duque, W., Ferré-Huguet, N., Domingo, J.L. and Schuhmacher, M. (2006). Assessing water quality in rivers with fuzzy inference systems: a case study. Environment International, 32(6): 733-742, https://doi.org/10.1016/j.envint.2006.03.009

ODEQ, (2014). Oregon Water Quality Index Summary Report, Water Years 2004-2013.

Ogunlela, A.O. and Adelodun, B. (2014). Kinematic flood routing of Asa River, ilorin, nigeria. International Journal of Engineering and Technical Research, 2(3): 13-17.

Parmar, K. and Parmar, V. (2010). Evaluation of water quality index for drinking purposes of river Subernarekha in Singhbhum District. International Journal of Environmental Science, 1: 77-81.

Phadatare, S.S. and Gawande, S. (2016). Review Paper on Development of Water Quality Index. International Journal of Engineering Research \& Technology, 5(5): 765-767.

Prati, L., Pavanello, R. and Pesarin, F., (1971). Assessment of surface water quality by a single index of pollution. Water Research, 5: 741-751.

Said, A., Stevens, D.K. and Sehlke, G. (2004). An Innovative Index for Evaluating Water Quality in Streams. Environmental Management, 34(3): 406-414, https://doi.org/10.1007/s00267-004-0210-y

Sargaonkar, A. and Deshpande, V. (2003). Development of an overall index of pollution for surface water based on a general classification scheme in Indian context. Environmental Monitoring and Assessment, 89(1): 43-67.

Sarkar, C. and Abbasi, S.A. (2006). Qualidex-new software for generating water quality indices. Environmental Monitoring and Assessment, 119(1-3): 201-231. 
Singh, S. and Hussian, A. (2016). Water quality index development for groundwater quality assessment of Greater Noida sub-basin, Uttar Pradesh, India. Cogent Engineering, 3: 1177155, http://doi.org/10.1080/23311916.2016.1177155

Smith, D.G. (1990). A better water quality indexing system for rivers and streams. Water Research, 24(10): 1237-1244.

Sutadian, A.D., Muttil, N., Yilmaz, A.G. and Perera, B.J.C. (2016). Development of river water quality indices-a review. Environment Monitoring Assessment, 188: 58, https://doi.org/10.1007/s10661-015-5050-0

Swamee, P. and Tyagi, A. (2007). Improved method for aggregation of water quality subindices. Journal of Environmental Engineering, 133(2): 220-225, https://doi.org/10.1061/(ASCE)0733-9372(2007)133:2(220)

Tiwari, T.N. and Mishra, M. (1985). A preliminary assignment of water quality index to major Indian rivers. Indian Journal of Environmental Protection, 5(4): 276-279.

Tyagi, S., Singh, P., Sharma, B. and Singh, R. (2014). Assessment of water quality for drinking purpose in District Pauri of Uttarakhand, India. Applied Ecology and Environmental Sciences, 2(4): 94-99, https://doi.org/10.12691/aees-2-4-2

Vasanthavigar, M., Srinivasamoorthy, K., Vijayaragavan, Rajiv Ganthi, R., Chidambaram, S., Anandhan, P., Manivannan, R. and Vasudevam, S. (2010). Application of water quality index for groundwater quality assessment: Thirumanimuttar sub-basin, Tamilnadu, India. Environmental Monitoring and Assessment; 171: 595-609, https://doi.org/10.1007/s10661-0091302-1.

Venkatramanan, S., Chung, S.Y., Ramkumar, T., Rajesh, R. and Gnanachandrasamy, G. (2016). Assessment of groundwater quality using GIS and CCME WQI techniques: a case study of Thiruthuraipoondi city in Cauvery deltaic region, Tamil Nadu, India. Desalination and Water Treatment, 57(26): 12058-12073.

Wagh, V.M., Panaskar, D.B., Muley, A.A. and Mukate, S.V. (2017). Groundwater suitability evaluation by CCME WQI model for Kadava river basin, Nashik, Maharashtra, India. Modeling Earth Systems and Environment, 3(2): 557-565.

Walski, T.M. and Parker, F.L. (1974). Consumers water quality index. ASCE Journal of Environmental Engineering Division, 100 (EE3): 593-611.

Wepener, V., Euler, N., Van Vuren, J.H.J., Du Preez, H.H. and Kohler, A. (1992). The development of an aquatic toxicity index as a tool in the operational management of water quality in the Olifants River (Knsger National Park). Koedoe, 35(2): 1-9.

Zotou, I., Tsihrintzis, V.A. and Gikas, G.D. (2019). Performance of seven water quality indices (WQIs) in a Mediterranean River. Environmental Monitoring and Assessment, 191: 505.

Cite this chapter as: Kamboj, V., Kamboj, N. and Bisht, A. (2020). An overview of water quality indices as promising tools for assessing the quality of water resources. In: Advances in Environmental Pollution Management: Wastewater Impacts and Treatment Technologies, Volume 1, Eds. Kumar, V., Kamboj, N., Payum, T., Singh, J. and Kumar, P., pp. 188-214, https://doi.org/10.26832/aesa-2020-aepm-013 